\title{
DESAIN SARANA BAWA PERLENGKAPAN PISAU UNTUK DISCOVERER
}

\author{
Andi Farid Hidayanto \\ Staf Pengajar Program Studi Desain Produk, Jurusan Desain \\ Politeknik Negeri Samarinda \\ Endah Retno Asih \\ Mahasiswa Program Studi Desain Produk, Jurusan Desain \\ Politeknik Negeri Samarinda
}

\begin{abstract}
ABSTRAK
Discovery adalah aktivitas yang penting untuk dilakukan, karena discovery mampu membuat pikiran menjadi rileks dan kembali fresh. Bagi para discoverer, pisau merupakan benda wajib yang perlu dibawa, karena pisau berperan penting. Selain pisau, banyaknya perlengkapan survival yang wajib dibawa ketika melakukan discovery, seperti perlengkapan navigasi, P3K, pembuat api, tali serbaguna, peniti, jarum, benang, perlengkapan memancing, dan cutter menuntut discoverer membawa tas khusus untuk mempermudah membawa perlengkapan tersebut. Karena sebelumnya perlengkapan tersebut hanya diletakkan di dalam carrier bersama perlengkapan lainnya, sehingga harus membongkar carrier saat perlengkapan tersebut akan digunakan. Tujuan dari perancangan ini adalah membuat sarana bawa yang dapat mengorganisir perlengkapan survival, khususnya pisau, sehingga saat membawa perlengkapan tersebut discoverer merasa aman dan nyaman. Dalam proses perancangan ini menggunakan metode perancangan model French yang meliputi analisis data, desain konseptual, desain awal, alternatif, pengembangan, desain terpilih, model, desain prototype, poster dan portofolio. Perancangan ini menghasilkan sebuah sarana bawa berupa tas khusus untuk membawa perlengkapan survival. Dengan inovasi baru yang lebih mengutamakan segi fungsi, tas ini diharapkan dapat menjadi sarana bawa yang praktis dan efisien untuk mempermudah discoverer membawa perlengkapan survivalnya.
\end{abstract}

Kata Kunci: Tas, pisau, survival, discovery 
Andi Farid Hidayanto, Endah Retno Asih, Desain Bawa Perlengkapan Pisau Untuk Discoverer

\section{ABSTRACT}

Discovery is an important activity to do, because discovery is able to make the mind become more relaxed and fresh again. For the discoverer, the knife is one of the things that must be brought. Because the knife has a very important role. In addition to knives, the number of survival equipment that must be taken when doing discovery such as navigation equipment, first aid, fire maker, multipurpose strap, pin, needle, thread, fishing equipment, and cutter Require the discoverer to carry a special bag to make it easier to carry the equipment because previously the equipment is only placed inside the carrier along with other equipment, so it must dismantle the carrier when the equipment will be used. The purpose of this design is to create a vehicle that can organize survival equipment, especially knives, so when carrying the equipment discoverer feel safe and comfortable. In this design process using French model design methods that include data analysis, conceptual design, initial design, alternative, development, selected designs, models, prototype designs, posters and portfolios. This design provides a means of carrying a special bag to carry survival equipment. With a new innovation that prioritizes the functional aspect, this bag is expected to be a practical and efficient means to facilitate the discoverer to bring the survival gear.

Keywords: Bag, knife, survival, discovery

\section{Latar Belakang}

Discovery adalah aktivitas yang penting untuk dilakukan, karena kegiatan discovery merupakan salah satu cara untuk membuat pikiran menjadi lebih rileks, lebih tenang dan kembali fresh. Kegiatan discovery juga merupakan salah satu cara mudah untuk mendapatkan wawasan tambahan yang lebih baik (Pertiwi. F, 2016).

Kegiatan discovery salah satunya dilakukan oleh para petualang. Bagi para petualang yang sering merambah hutan dan gunung, pisau adalah benda yang wajib dibawa. Karena saat berpetualang, pisau berperan penting. Lebih dari itu, pisau juga berfungsi melindungi diri. Jika pisau tidak diletakkan pada tempat khusus akan berbahaya bagi pengguna. Selain pisau, ada beberapa perlengkapan survival lainnya yang dibawa ketika melakukan aktivitas pendakian, seperti senter, kompas, peralatan $\mathrm{P} 3 \mathrm{~K}$, peluit, fire steel (pembuat api), tali serbaguna (webbing tape), peniti, jarum jahit, benang, mata pancing dan senar pancing (Pertiwi. F, 2016).

Hasil survey mengatakan bahwa pisau yang tumpul ternyata menyebabkan lebih banyak kecelakaan dibanding yang tajam. Karena, dengan menggunakan pisau tumpul akan membutuhkan tenaga yang lebih pada saat memotong, dan karena tenaga yang berlebihan tersebut kontrol terhadap pisau akan berkurang, karena akan terfokus dalam mengeluarkan tenaga dibandingkan mengontrol pisau dan ini berbanding terbalik dengan pisau yang tajam, dimana pisau tajam hanya membutuhkan tenaga yang sedikit untuk menuntaskan perkerjaan. Banyaknya perlengkapan survival yang wajib dibawa ketika melakukan discovery menuntut discoverer membawa tas khusus untuk mempermudah membawa perlengkapan tersebut karena sebelumnya perlengkapan tersebut hanya diletakkan di dalam carrier bersama perlengkapan lainnya, sehingga harus membongkar carrier saat perlengkapan tersebut akan digunakan. Selain itu, sarana bawa yang digunakan saat 
Vol. 4, No. 2, April 2017

ini masih berupa wadah serbaguna yang ditempatkan dengan perlengkapan lainnya, sehingga tingkat keamanan saat membawanya sangat rendah.

Berdasarkan latar belakang di atas, maka dibutuhkan sarana bawa pisau yang khusus didesain untuk discoverer yang dapat mencakup semua peralatan survival khususnya pisau pada saat melakukan kegiatan discovery tanpa harus membongkar tas carrier saat peralatan tersebut akan digunakan.

\section{METODE PERANCANGAN}

Dalam mendesain sarana bawa perlengkapan pisau untuk discovery ini menggunakan metode perancangan model French agar mudah dipahami dan dipraktekkan. Berikut langkah-langkah perancangan menurut metode perancangan model French:

\subsection{Need (Kebutuhan)}

Need atau kebutuhan, menjelaskan tentang berbagai kebutuhan yang diperoleh dari permasalahan produk yang sudah ada sehingga perlu didesain sarana bawa perlengkapan pisau untuk discoverer tesebut.

\subsection{Analisis Masalah}

Yaitu menganalisis permasalahan, data dan informasi pada produk yang muncul, baik produk yang sudah ada maupun menganalisis masalah yang muncul ketika produk digunakan oleh pengguna serta mencari kekurangan dan kelebihan pada produk yang sudah ada.

\subsection{Pernyataan Masalah}

Pernyataan masalah merupakan penulisan berbagai masalah yang terdapat pada produk yang telah dianalisis baik data maupun informasi yang terdapat pada produk yang sudah ada yang telah dirumuskan.

\subsection{Desain Konseptual}

Berdasarkan beberapa permasalahan yang telah dianalisis, maka diperlukan suatu konsep desain. Konsep desain tersebut akan menjadi acuan untuk proses desain berikutnya meliputi sistem, warna maupun bentuk produk.

\subsection{Rencana Terpilih}

Dalam mendesain ini, merencanakan proses desain yang meliputi desain awal yang sesuai konsep, desain alternatif, pengembangan desain sampai dengan desain terpilih.

\subsection{Perwujudan Rencana}

Perwujudan rencana dalam proses mendesain produk ini meliputi desain awal yang perwujudannya melalui sketsa- sketsa yang telah dibuat, kemudian sketsa-sketsa tersebut akan dipilih satu untuk dijadikan desain terpilih dan dikembangkan desain alternatifnya.

\subsection{Perincian}

Perincian yang dimaksudkan adalah hasil dari tahapan- tahapan metode yang digunakan dan dijabarkan dalam spesifikasi teknik desain yang meliputi material yang digunakan, sistem, bentuk, warna, dimensi produk dan lain-lain.

\subsection{Pengerjaan}

Pengerjaan desain produk ini meliputi penyusunan laporan, desain awal, desain alternatif, pengembangan desain, sketsa desain terpilih, model, desain prototype produk, poster, portofolio, dan gambar teknik. 
Andi Farid Hidayanto, Endah Retno Asih, Desain Bawa Perlengkapan Pisau Untuk Discoverer

III. Pembahasan

\subsection{Analisis Pasar}

Analisis pasar dilakukan guna menentukan sasaran pengguna produk yang dirancang. Penentuan target pasar dapat dilakukan berdasarkan pendekatan- pendekatan sebagai berikut :

a. Demografi

Berdasarkan Demografi, target pasar produk ini dapat dibagi berdasarkan gender, pekerjaan dan kelas sosial pengguna produk tersebut. Berdasarkan gender, pengguna produk ini didesain khusus untuk pengguna laki-laki karena produk tersebut dirancang dengan stlyling pelaku kegiatan discovery yang umumnya dilakukan oleh laki-laki. Kegiatan discovery ini umumnya dilakukan oleh orang-orang yang memiliki hobi discovery, selain itu kegiatan ini dilakukan untuk mengisi waktu luang. Berdasarkan pekerjaan, pengguna produk ini adalah kalangan umum yang mayoritas laki-laki dan memiliki hobi discovery. Berdasarkan kelas sosial, pengguna produk ini adalah kelas menengah.

b. Manfaat

Berdasarkan Manfaat, target pasar produk ini dapat dibagi berdasarkan manfaat utama produk dan tipe pengguna yang mencari tiap-tiap manfaat produk sarana bawa perlengkapan pisau tersebut. Berdasarkan manfaat utama, produk ini didesain khusus untuk memberikan keamanan dan mempermudah discoverer saat membawa atau menyimpan perlengkapan pisau yang dibawa saat melakukan aktivitas discovery. Selain itu, produk ini juga didesain untuk menunjukkan style atau gaya hidup.
Berdasarkan tipe pengguna, produk ini didesain khusus untuk pengguna yang memiliki tipe atau pengguna yang suka berpetualang atau memiliki hobi discovery.

\subsection{Analisis Studi Aktivitas dan Kebutuhan}

Analisis aktivitas dan kebutuhan dilakukan untuk mengetahui aktivitas apa saja yang dilakukan oleh pengguna produk. Setelah melakukan analisis aktivitas akan diketahui kebutuhan komponen-komponen yang harus pada produk yang akan dibuat.

Beberapa perlengkapan survival yang wajib dibawa ketika melakukan aktivitas discovery diantaranya adalah senter, kompas, pisau serbaguna, peralatan $\mathrm{P} 3 \mathrm{~K}$, peluit, fire steel (pembuat api), tali serbaguna (webbing tape), peniti, jarum jahit, benang, mata pancing dan senar pancing. Adapun analisis aktivitas dan kebutuhan desain sarana bawa perlengkapan pisau untuk discoverer adalah sebagai berikut: 1) Membawa Pisau Khusus Untuk Kegiatan Discovery, 2) Membawa Perlengkapan Navigasi, 3) Membawa dan Menyimpan Rain Cover, 4) Membawa dan menyimpan perlengkapan P3K, 5) Membawa dan Menyimpan Perlengkapan Memancing, 6) Membawa dan Menyimpan Jarum Jahit, Benang Dan Peniti, 7) Membawa dan Menyimpan Atau Tali Serbaguna (Webbing Tape)

\subsection{Analisis Ergonomi dan Anthropometri}

Dalam merancang sebuah produk, analisis ergonomi dan anthropometri diperlukan karena setiap pembuatan produk yang berhubungan dengan manusia harus mengutamakan faktor kenyamanan dalam penggunaan produk tersebut. 
a. Analisis Ergonomi

Dalam merancang produk, kenyamanan pengguna dalam menggunakan atau membawa sarana bawa perlengkapan pisau ditentukan oleh ukuran-ukuran dimensi tubuh manusia yang menggunakan produk tersebut.

Pada perancangan produk ini, berikut beberapa analisis yang perlu diperhatikan :

- Batas maksimal angkat yang digunakan adalah batas angkat maksimal pria usia 18 tahun agar produk juga dapat mencakup keamanan dan kenyamanan pengguna pria dewasa. Batas angkat maksimal pria usia 18 tahun adalah $18 \mathrm{~kg}$. jadi berat total produk sarana bawa perlengkapan pisau tidak boleh lebih dari $18 \mathrm{~kg}$.

- Sarana bawa perlengkapan pisau untuk discoverer ini memiliki beberapa kantong khusus untuk membawa ataupun menyimpan perlengkapan discovery yang disesuaikan dengan masing-masing jenis perlengkapan agar perlengkapan tersebut tidak tercampur dengan perlengkapan lainnya.

- Tas dilengkapi tali Webbing yang panjang pendeknya dapat diatur sesuai dimensi paha discoverer.

\section{b. Analisis Anthropometri}

Berikut adalah analisis anthropometri pada produk :

- Lebar kantong pada tas diambil dari ukuran tebal tangan dan lebar telapak tangan $95 \%$ tile pria dengan ukuran tebal $2,8 \mathrm{~cm}$ dan lebar tas $6,8 \mathrm{~cm}$. Ukuran ini adalah ukuran maksimal. Ukuran produk tas yang dirancang adalah tebal tas $2 \mathrm{~cm}$ dan lebar kantong
$9 \mathrm{~cm}$.

- Lebar tas diambil dari ukuran lingkar paha atas dan paha bawah $50 \%$ tile pria dengan ukuran $25 \mathrm{~cm}$. ukuran ini adalah ukuran maksimal. Ukuran produk tas yang dirancang adalah $22 \mathrm{~cm}$.

- Lebar tali tas bagian pinggang diambil dari ukuran lebar pinggul ukuran $5 \%$ tile pria dengan ukuran $30 \mathrm{~cm}$. ukuran ini adalah ukuran maksimal. Ukuran produk tas yang dirancang adalah 80 $\mathrm{cm}$.

\subsection{Analisis Konfigurasi}

Analisis konfigurasi untuk menentukan peletakkan yang tepat bagi perlengkapan pisau yang akan dibawa oleh discoverer menggunakan sarana bawa ini. Adapun komponen yang ada pada produk sarana bawa perlengkapan pisau adalah : 1) Tempat penyimpanan pisau, 2) Tempat penyimpanan rain cover, 3) Tempat penyimpanan senter, 4) Tempat penyimpanan kompas, 5) tempat penyimpanan GPS, 6) Tempat penyimpanan peluit, 7) Tempat penyimpanan pembuat api (fire steel), 8) Tempat perlengkapan $\mathrm{P} 3 \mathrm{~K}$, 9) Tempat penyimpanan tali serbaguna (webbing),10) Tempat penyimpanan perlengkapan memancing, dan 11) Tempat penyimpanan jarum, benang dan peniti. Dari analisis yang telah dilakukan, terpilih konfigurasi produk yang ditunjukkan dalam gambar 1 di bawah: 
Andi Farid Hidayanto, Endah Retno Asih, Desain Bawa Perlengkapan Pisau Untuk Discoverer

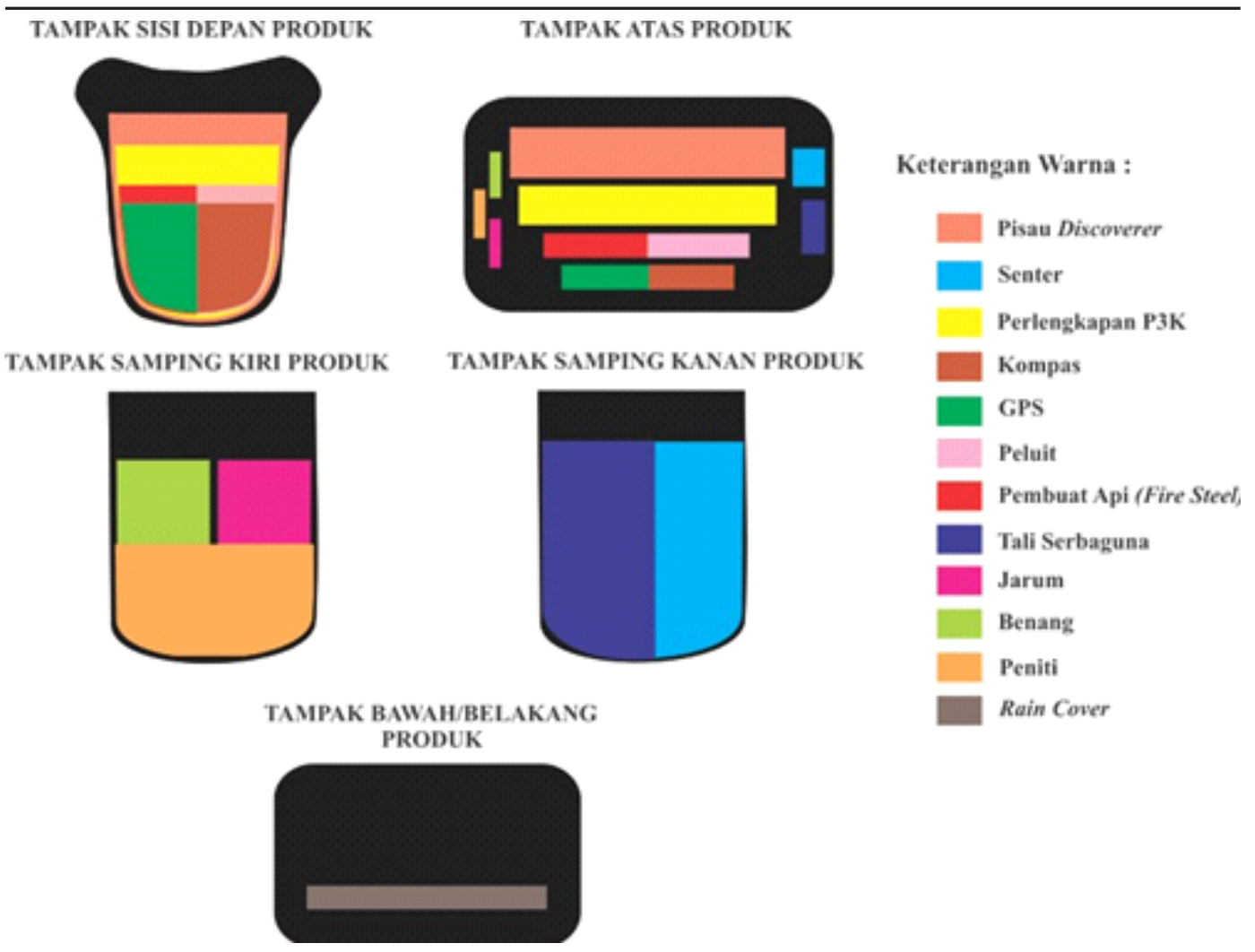

Gambar 1. Konfigurasi produk

Pada konfigurasi dalam gambar 1, kantong kantong khusus untuk penyimpanan pisau disusun dibagian paling belakang dan mempunyai dimensi yang paling besar sehingga mempermudah discoverer ketika mengambil dan meletakkan pisau, serta berat beban pada sarana bawa perlengkapan pisau untuk discoverer juga menjadi seimbang. Selain itu, beberapa kantong-kantong yang diletakkan pada samping kanan dan kiri produk juga akan mempermudah dan mempersingkat waktu yang dibutuhkan oleh discoverer saat akan mengambil perlengkapan seperti senter dan tali serbaguna serta perlengkapan lainnya tanpa harus membuka kantong bagian dalam tas.

\subsection{Analisis Sistem}

Analisis sistem dilakukan untuk menentukan sistem yang sesuai untuk diaplikasikan pada produk yang akan dibuat.
Adapun sistem-sistem yang akan digunakan pada poduk sarana bawa pisau untuk discoverer sebagai berikut :

\section{- $\quad$ Sistem Buka Tutup}

Berdasarkan analisis kelebihan dan kekurangan sistem buka tutup menggunakan kancing tipe Magnetic Snap Button. Sistem bukaan ini digunakan untuk menutup sekaligus mengunci sekat-sekat atau kantong kecil diluar kantong utama. System bukaan ini juga praktis untuk diaplikasikan pada tas, karena cara menggunakan kuncian ini cukup mudah, hanya dengan mengatupkan kedua sisi kancing dan kemudian magnet yang terdapat dalam kancing akan menjaga kuncian tetap rapat. Adapun pemasangannya disesuaikan berdasarkan bagian-bagian terpilih yang sesuai dengan fungsinya. 
Vol. 4, No. 2, April 2017

- $\quad$ Sistem Bukaan Resleting (Zipper)

Berdasarkan analisis sistem bukaan jenis resleting (zipper) yang telah dilakukan, zipper yang sesuai untuk diaplikasikan pada produk adalah zipper dengan single slider, yaitu zipper atau resleting yang memiliki satu arah bukaan. Zipper tipe ini juga simple dan ringkas.

- Sistem Sambungan

Berdasarkan analisis sistem sambungan jenis jahitan yang telah dilakukan, sistem sambungan yang sesuai untuk diaplikasikan pada produk adalah sitem jahitan kunci, bordir dan jahitan terikat (Bound). Jenis jahitan kunci dipilih untuk diaplikasikan sebagai sistem sambungan produk karena jenis jahitannya kuat saat diaplikasikan pada material yang tebal yaitu Baby Ripstop yang dilapis dengan busa ati, busa Polyfoam kanvas pada bagian dalamnya, selain itu jenis jahitan ini adalah jenis jahitan yang umum digunakan. Jenis jahitan Tumpang (Superimposed) pada setiap bagian pola produk yang terdiri dari 3 lapisan (kulit sintetis pada bagian luar, busa Ati dan busa Polyfoam dibagian tengah dan Parasut sebagai lapisan dalam), jenis jahitan ini sesuai untuk diaplikasikan pada produk karena jenis jahitan ini digunakan untuk material 2 lapis atau lebih. Sedangkan pada sisisisi tepi produk dan kantong-kantong yang terdapat pada produk, jahitan dibuat terlihat, maka jenis jahitan yang diaplikasikan adalah jenis jahitan terikat (Bound), sehingga jenis jahitan Bound terlihat rapi. Jenis jahitan ini dilakukan dengan cara menghubungkan kain penyambung (Webbing Tape) di atas pinggiran atau tepi kain yang ingin dihubungkan satu sama lain.
- Sistem Kuncian

Berdasarkan analisis yang telah dilakukan, sistem kuncian yang sesuai untuk diaplikasikan pada produk adalah sistem kuncian Side Release Buckles dan Ladder Lock Buckles. Karena selain kuat, Side Release Buckles dan Ladder Lock Buckles juga tahan lama sehingga sesuai apabila diaplikasikan pada produk sarana bawa perlengkapan pisau untuk discoverer.

\subsection{Analisis Material}

Analisis material dilakukan untuk menentukan material yang sesuai untuk diaplikasikan pada produk yang akan dibuat. Kebutuhan material produk harus tebal, kuat, tahan air, tidak mudah robek, dan aman digunakan, oleh karena itu, menggunakan analisis material 3 bagian lapisan yang akan menghasilkan kualitas yang bagus dan awet. Jenis-jenis pelapis dibagi menjadi 3 bagian yaitu lapisan pertama atau disebut juga lapisan luar, lapisan antara (interlining), dan lapisan dalam (interfacing).

\section{- Material Pelapis Pada Lapisan Pertama atau Terluar}

Dalam memilih material yang digunakan untuk lapisan utama syaratsyarat yang harus dipertimbangkan antara lain adalah material yang digunakan harus tebal, kuat, tidak mudah robek, dan tahan air (waterproof). Berdasarkan analisis yang telah dilakukan, material pelapis pada lapisan utama atau terluar tas yang sesuai adalah kain Baby Ripstop. Karena dengan ketahanan kainnya yang lebih tebal dan kuat jika dibandingkan dengan bahan Cordura, Baby ripstop memiliki beragam pilihan warna yang kalem dan karakter warnanya doff. Karakter warnanya cocok untuk dipadukan dengan pengguna pria dan wanita segala usia. Baby Ripstop juga memiliki harga yang terjangkau, sehingga lebih bersahabat dibandingkan harga bahan 
Andi Farid Hidayanto, Endah Retno Asih, Desain Bawa Perlengkapan Pisau Untuk Discoverer

Cordura. Baby Ripstop dapat melindungi perlengkapan yang ada di dalamnya dari cuaca dingin. Secara konstruksi seratnya, menggunakan bahan dasar benang Nylon (Nilon) yang dikombinasikan dengan kapas, sutra, polyester, dan polypropylene sehingga baby ripstop memiliki filamen yang rapat, halus, kuat dan tahan lama.

\section{- Material Pelapis Pada Lapisan Antara (Interlining)}

Dalam memilih material yang digunakan untuk apisan antara (interlining), syarat-syarat yang harus dipertimbangkan antara lain adalah material yang digunakan harus tebal, kuat dan lebih kokoh dari material pelapis utama dan mampu memperkokoh dan menguatkan bentuk tas. Berdasarkan analisis yang telah dilakukan, material pelapis pada lapisan antara (interlining) tas yang sesuai adalah busa ati dan busa Polyfoam. Dengan tekstur padat dan kenyal, material ini sesuai diaplikasikan pada bagian kantong yang digunakan untuk membawa atau menyimpan pisau. Busa Polyfoam mampu mempertahankan bentuk dasar produk dan melindungi perlengkapan yang ada di dalamnya.

\section{- Material Pelapis Pada Lapisan Dalam (Interfacing)}

Dalam memilih material yang digunakan untuk lapisan paling dalam (interfacing) syarat-syarat yang harus dipertimbangkan antara lain adalah material harus tebal, kuat tidak mudah lembab dan lebih kokoh dari material pelapis utama dan mampu memperkokoh dan menguatkan bentuk tas. Berdasarkan analisis yang telah dilakukan, material pelapis pada lapisan ke tiga yaitu lapisan dalam (interfacing) yang sesuai untuk diaplikasikan adalah material kain Kanvas. Sifat yang dimiliki kain Kanvas akan mampu melindungi pengguna saat membawa atau menyimpan pisau dan perlengkapan survival lainnya pada produk.

\section{- Webbing Tape}

Webbing merupakan tali yang berbentuk pita, terbuat dari bahan nylon. Webbing sering digunakan sebagai tali tambahan pada tas. Webbing Tape digunakan sebagai penutup tepi jahitan pada bagian luar produk sarana bawa perlengkapan pisau untuk discoverer. Selain itu, Webbing Tape juga digunakan sebagai tali penghubung antara produk dengan Hook Loop.

\subsection{Analisis Bentuk dan gaya}

Analisis bentuk diperlukan dalam menentukan bentuk yang sesuai yang akan diterapkan pada produk. Dalam mendesain ini, berdasarkan beberapa pendekatan bentuk yang telah dianalisis, pendekatan bentuk yang akan dilakukan adalah berdasarkan jenis tas dan gaya desain. Berdasarkan analisis yang dilakukan, jenis tas yang dipilih untuk diterapkan pada produk adalah jenis tas paha. Jenis tas ini simpel dan sesuai apabila diaplikasikan pada sarana bawa perlengkapan pisau untuk discoverer. sehingga akan memudahkan pengguna dalam membawa perlengkapan pisau dan perlengkapan survival lainnya dan tidak perlu membongkar carrier kembali saat akan mengambil atau menyimpan perlengkapan tersebut.

Selain analisis kelebihan dan kekurangan diatas, pendekatan bentuk juga dilakukan berdasarkan gaya desain. Gaya desain yang sesuai untuk diaplikasikan pada produk adalah gaya desain modern. Gaya modern dipilih karena bentuknya yang geometris dan simple, cocok dengan karakter pria yang cenderung menyukai bentuk- bentuk yang sederhana dan simple. Bentuk simpel dipilih, karena menyesuaikan dengan aktivitas discovery yang membutuhkan suatu sarana bawa dengan bentuk yang tidak rumit serta pemakaiannya yang praktis. 
Vol. 4, No. 2, April 2017

\subsection{Analisis Warna}

Analisis warna diperlukan guna menentukan warna yang sesuai untuk diaplikasikan pada produk. Pendekatan yang digunakan adalah hubungan warna dengan psikologi pengguna produk. Berdasarkan analisis yang dilakukan, warna yang sesuai untuk diterapkan pada produk adalah warna hitam dan warna orange. Warna hitam dipilih sebagai warna dominan karena warna hitam adalah awarna yang mudah untuk dikombinasikan dengan warna lain. Warna hitam dipersepsi sebagai ketenangan, keheningan dan fokus, selain itu warna hitam juga dipersepsi sebagai kekuatan, warna yang elegan, kuat, gagah dan perkasa. Warna orange diterapkan sebagai aksen karena warna orange dipersepsi sebagai energi bagi adventurer, pemberani dan out of box, petualangan, rasa percaya diri, pergaulan luas, optimisme, fun \& entertaining, sesuai dengan produk. Selain itu warna orange juga memberikan kesan vitalitas, inspiration dan antusiasme yang dapat merangsang keinginan untuk keluar dan exploring baik dalam petualangan maupun sosial. Warna orange mampu menimbulkan kesan modern dan dapat dikombinasikan dengan hitam sebagai lambang keberanian bertualang, selain itu warna orange juga mampu mengimbangi warna hitam yang dominan.

\subsection{Proses desain}

Dalam mendesain produk ini, langkah awal adalah membuat desain awal dalam beberapa desain alternatif. Alternatif - alternatif ini selanjutnya dianalisis kelebihan dan kekurangannya serta kesesuian dengan spesifikasi dengan gaya dan bentuk yang akan dipakai. Dari beberapa alternatif tersebut akan terpilih alternatif yang memenuhi ketentuan yang dipersyaratkan. Selanjutnya alternatif terpilih tersebut dikembangkan lagi menjadi beberapa desain pengembangan sampai didapatkan desain final. Desain final ini dijabarkan menjadi desain akhir yang baku dilengkapi spesifikasi teknis, agar siap diproduksi. Spesifikasi teknis tersebut meliputi gambar presentasi, gambar teknik, material, sistem, proses produksi, dan biaya produksi. Adapun tahapan desain tersebut ditunjukkan dalam gambar gambar di bawah ini.

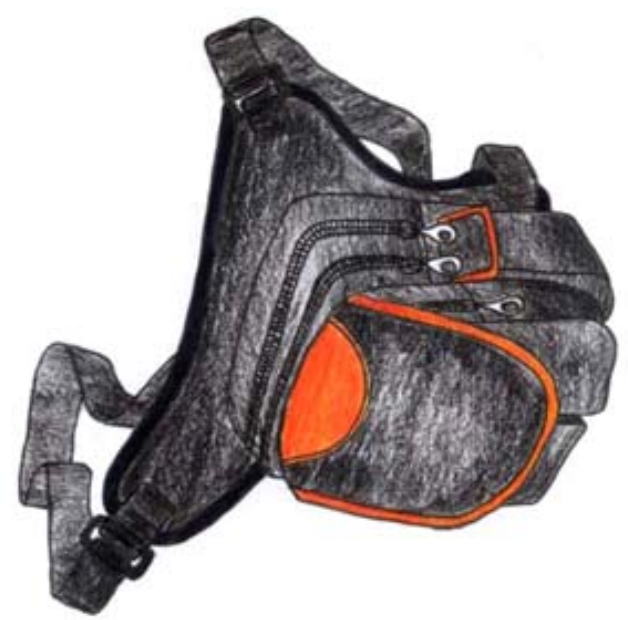

Gambar 2. Desain awal

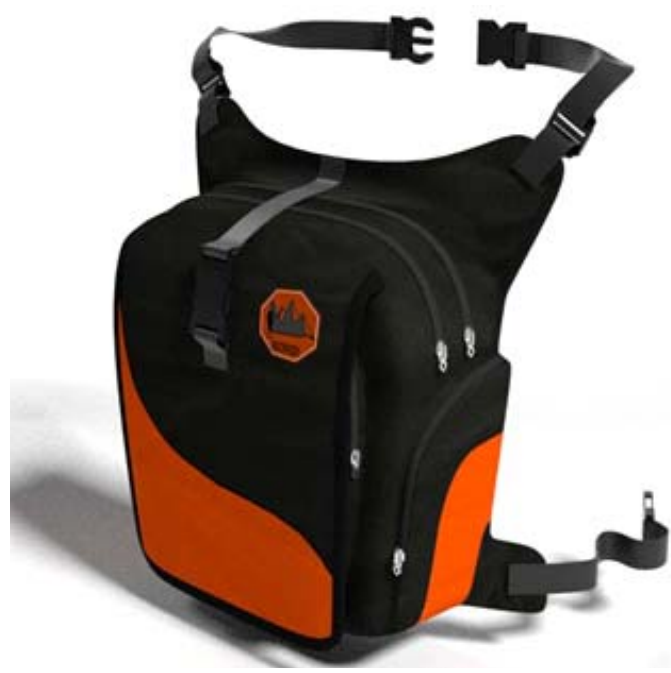

Gambar 3. Desain pengembangan 
Andi Farid Hidayanto, Endah Retno Asih, Desain Bawa Perlengkapan Pisau Untuk Discoverer

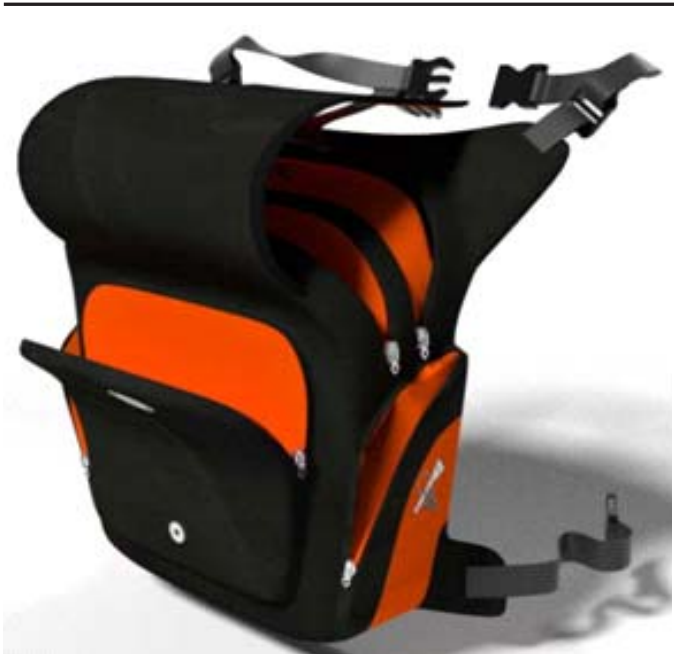

Gambar 4. Desain pengembangan
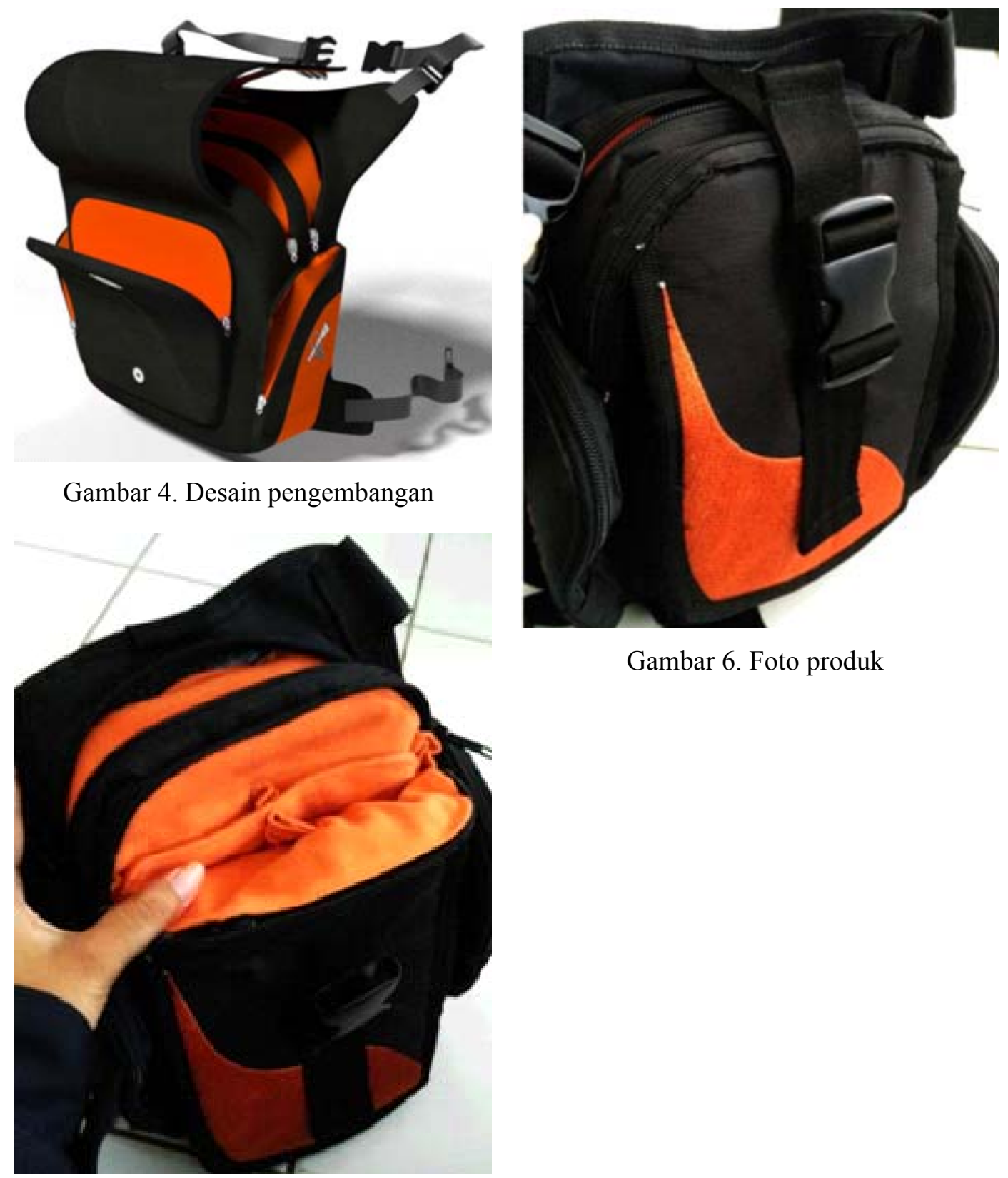

Gambar 6. Foto produk

Gambar 5. Foto Produk 


\section{Kesimpulan}

Berdasarkan hasil dari perancangan Desain Sarana Bawa Perlengkapan Pisau Untuk Discoverer, maka dapat ditarik kesimpulan:

- Produk yang dihasilkan dapat mengakomodir perlengkapan survival yang dibawa oleh discoverer saat melakukan kegiatan discovery, karena sarana bawa yang dihasilkan dilengkapi dengan kantong dan sekat- sekat khusus untuk membawa dan menyimpan perlengkapan pisau discovery.

- Produk yang dihasilkan dihasilkan nyaman saat digunakan untuk membawa perlengkapan discoverer, karena sarana bawa tersebut memiliki ukuran yang sesuai dengan dimensi tubuh serta memiliki tali tas yang adjustable sehingga mudah diatur panjang pendeknya.

- Produk yang dihasilkan dihasilkan dirancang dengan bentuk yang modern dengan sistem bukaan, sambungan dan kuncian yang tidak rumit, dan menggunakan material yang kuat dan tebal.

Perancangan produk ini ke depannya diharapkan bisa memberi nilai tambah, dengan bentuk yang lebih menarik, agar dapat menjadi produk yang lebih diminati oleh konsumen. Penelitian lanjutan mengenai aktivitas konsumen yang berkaitan dengan produk yang diracang juga dapat memberikan nilai tambah produk tersebut karena kebutuhan konsumen telah terpenuhi.

Dalam perancangan produk ini masih terdapat beberapa kekurangan. Untuk mendapatkan hasil yang maksimal perlu adanya pengembangan lebih lanjut. Ke depannya diharakan adanya perancangan lanjutan mengenai sarana bawa khusus perlengkapan pisau untuk discoverer. 
Andi Farid Hidayanto, Endah Retno Asih, Desain Bawa Perlengkapan Pisau Untuk Discoverer

\section{DAFTAR RUJUKAN}

Amstrong, Gary., \& Kotler, Philip (2004). Dasar-Dasar Pemasaran. Jakarta: PT. Indeks

Cahyadi, Dwi. (2014). Aplikasi Mannequin Pro Untuk Desain Industri. LeutikaPrio: Yogyakarta.

Nurmianto, Eko. (1996). Ergonomi, Konsep Dasar dan Aplikasinya. PT. Guna Widya: Surabaya.

Kamus Besar Bahasa Indonesia, (1999). Balai Pustaka : Jakarta.

Ginting, Rosnani. (2010). Perancangan Produk. Graha Ilmu: Yogyakarta.

Annjana. (2015). Macam Bahan Pekapis Tas. Diakses Maret 10, 2017. http:// www.annjana.com/2015/06/macam-bahan-pelapis-tas.html

Aristiawan, Fuady Luqman. (2015). Warna Dalam Multimedia. Diakses Maret 02, 2017. https://aris83.wordpress.com/2015/12/13/warna-dalam-mu lt imedia

Dewi, Nur Rosita. (2016). Jenis-jenis Tas Pria. Diakses Maret 03, 2017. https:// jurnal.maskoolin.com/jurnal/fashion/mengenal-10- jenis-tas-pria/

Fitinline. (2013). Jenis-jenis Kancing. Diakses Maret 10, 2017. https://fitinline.com/ article/read/jenis-kancing/

Fitinline. (2015). Jenis Resleting Berdasarkan Bahan Baku Pembuatannya. Diakses Maret 10, 2017. https://fitinline.com/article/read/7-jenis-resleting-berdasarkan-bahanbaku- pembuatannya/

Fitinline. (2015). Kain Spunbond. Diakses Maret 10, 2017. https://fitinline.com/article/ read/kain-spunbond/

Fitinline. (2014). Jenis-jenis kain parasut. Diakses Maret 10, 2017. https://fitinline.com/ article/read/jenis-jenis-kain-parasut/

Fitinline. (2016). Jenis Bahan Yang Dapat Digunakan Sebagai Pelapis Tas. Diakses Maret 10, 2017. https://fitinline.com/article/read/9-jenis-bahan-yang-dapat-digunakan-se bagai-pelapis-tas/

Fitinline. (2017). Mengenal Webbing Tas. Diakses Maret 10, 2017. https://fitinline.com/ article/read/mengenal-webbing-tas/

Fitinline. (2014). Vintage Style. Diakses Maret 10, 2017. https://fitinline.com/article/read/ vintage-style

Hakim, Zainal. (2012). Jenis Aplikasi Pengolah Desain Grafis. Diakses Januari 17, 2017. www.zainalhakim.web.id/posting/jenis-aplikasi-pengolah-desain- grafis.html02/Juli/2012 
Vol. 4, No. 2, April 2017

Ifan. (2016). Bahan Yang Sering Digunakan Membuat Tas. Diakses Maret 10, 2017. http://konveksitasonline.com/bahan-yang-sering-digunakan-membuat-tas

Johan. (2012). Pengertian dan Arti Warna. Diakses Maret 15, 2017. http:// www.ilmugrafis.com/pengertian-arti-warna

Mangkoko. (2016). Psikologi Warna. Diakses Maret 02, 2017. http://mangkoko.com/ ruang baca/psikologi-warna-biarkan-warna-berbicara: 23 Desember 2016).

Pertiwi, Ni Luh Made, F. (2016). Pentingnya Travelling. Diakses Februari 04, 2017. http://travel.kompas.com/read/2016/06/08/201100227/

Pentingnya.Traveling.Ini.Efek.Liburan.pada.Tubuh.

Ubay Fahry. (2015). Efek Warna Dalam Desain Grafis Dan Psikologinya. Diakses Maret 03, 2017. http://klo pidea.com/efek-warna-dalam-desain-grafis-dan-psikologinya/

Zalva, Anisa. (2016). Jenis Tusuk Hias Yang Sering Digunakan. Diakses Maret 10, 2017. http://www.kreasiceria.com/2016/06/10-jenis-tusuk-hias-yang-sering-digunakan.ht $\underline{\mathrm{ml}}$ 